\title{
Effects of silo mentality on corporate ITC's business model
}

\author{
Tshidi MOHAPELOA \\ Rhodes Business School, Grahamstown, South Africa \\ t.mohapeloa@ru.ac.za
}

\begin{abstract}
Background \& orientation: The existence of silo mentality has direct effect on the business model used by any ITC company. Its contribution slows service delivery whilst increasing customer's despondency. However mitigation could help overcome barriers within divisions, improve customer experience and increase productivity. But when different units as components of a company fail to integrate, collaborate and work together to achieve a common objective goal, not only are performances affected but also operations at all levels. A business model canvas can help determine how a company intends to create value for customers whilst it makes money. Thus deliverance of an effective value proposition for efficient customer needs, can be affected through silos. Purpose: This study explore the effects of silo mentality within an ITC company (at organisational level) using the 9 elements of the business model canvas as framework. Methodology and research questions: As an exploratory study qualitative methods were used where in-depth interview questions looked at how silo mentality within the organisation affects the core business model elements and why. Twelve participants were selected from an enterprise business unit through a convenience sampling method. Content analysis helped with the development of core themes that looked at the how silos affect each element (process) and why (meaning). Findings: Silo mentality affects not only the individuals but team, products, value proposition, relations with partners, customers, stakeholders. Thus undermines internal capabilities and key resources. Absence of teamwork within the divisions leads to conflicts which delays achievements of common goals. Bottlenecks affect inter-divisional progress and relations, customer output and relations and compromise the quality of service. Implications: Silo mentality is a bottleneck that not only weakens firms' capabilities and growth potential but destroys any value created by the firm.
\end{abstract}

Keywords: silo mentality, business model canvas, ITC firm, qualitative research, content analysis.

\section{Introduction}

Globally the telecommunication industry has been revolutionised since the inception of mobile phones, decline of the market share in the fixed line communication, with growth in broadband/ bandwidth for faster internet access. The Information Technology and Communication (ITC) industry has attracted competitors on alternatives to the fixed lines from both mobile and fixed lines suppliers. Competing for a share in the market in a closed, tight and congested ITC space with rapidly changing customer demands can collapse a sector. Howevever, an interdepartmental competition within an organisation affects people, products, processes in both negative and positive manner. Positive effects occurs when productivity and output increase whilst negative outcomes occur when interdepartmental competition consequences are linked to the sins of silo mentality.

Silo is an attitude that occurs when several departments or groups do not want to share information or knowledge with other individuals in the same company. Thus inconsistency in responding to changing demands such as withholding crucial information, led to departments working in silos, a distraction that distabilises the operation of the business (Syverson, 2010). Consequences of silo such as customer reduction, failure to meet customer requirement (in line with the organisational structure, vision and mission), incoherent working amongst employees are some of the problems observed within this ITC Company. Silo mentality, a concept defined as a lack of communication and common goals between departments in an organisation (Hotaran, 
2009:216). When employees' incoherent work occurred, customer decline was observed and operations in a value chain failed to meet customer requirements. Thus a need to explore the effects of silo mentality in a large ITC company.

For an company to remain relevant it needs to create, deliver and capture value through people, products and processes. Meaning its business model should clearly indicate how the value proposition, value constellation and revenues are gained. Business model enhance productivity and increases output yet, consequences and sins of silo mentality has the oppoiste effects. The aim of this study is to investigate how silo mentality affects business model elements of an ITC company.

\section{Review of literature}

Organisational effects of silo mentality cannot be discussed without exploring literature from psychoanalysis and the group dynamics as this affects the social behaviour of teams within an organisation. Organisational psychodynamics is defined as the study of unconscious patterns of work relations (Adams and Diamond, 1999). However its direct influence on other core aspects such as leadership, role formation, conflict, identity, boundaries and authority cannot be ignored (Celliers and Greyvenstein, 2012). Psychodynamic literature views silos as an organisational metaphor in the systems (Diamond and Allcorn, 2004, 2009; Diamond, Stein and Allcorn, 2002; Diamond, Allcorn and Stein, 2004). They defined organisational silos as vast psychological spaces of compartmentalisation, segregation and differentiation. Celliers and Greyveinstein (2012) further highlighted that silo mentality impacts team identity at four levels (1) physical environment and departmental structure, (2) intra-group relations, experiences of management and (4) intergroup relations. This suggests that there are different components of an organisation that have bearing effect in the silo mentality. However, the impact they possess can effectively change the behaviour not only of the organisation but that of an individual.

Understanding organisational behaviour looks at the systematic processes that affects the behaviour of more than two people in terms of actions and attitudes (Frederick 2014) application of knowledge and working relation (Bauer and Erdogan, 2012). However Frederick (2014) further explored the organisation as a consciously coordinated social unit functioning on a continuous basis to achieve a common goal or set of goals. This further highlighted aspects such as group identity (Volkan, 2009) and organisational identity (Whetten, 2006). Group identity has been defined in a subjective manner based on people sense of sameness (Volkan, 2009), whereas Whetten (2006) focus on the core and enduring attributes of an organisation. Both focus on the belonging-ness as determining factor for identity. This can be determined through the sharing of values and beliefs, as these makes one group distinctive from the other (Betchoo, 2015).

\section{Effects on the individual firm levels}

The definitions and usage of silo mentality is diverse as others use it as metaphor for dysfunctional organisational fragmentations, disconnectedness, dissociation (Greenberg and Baron, 2003; Celliers and Greyvenstein, 2012). Feelings of powerlessness, and lack of trust, tend to consume those affected by silo mentality. As an invisible barrier silos tend to exist in the mind as they are not physically present in organisations, occupy employee's mind especially those with shared impression of organisational reality (Cilliers and Greyvenstein, 2012; Diamond and Allcorn, 2009). Silo mentality tends to be formed when there is constant shift within the organisations, influenced by the ongoing 
human changes (Vermeulen, Puranam and Gulati, 2010) yet, Katunzi (2011) highlights the failure to see the bigger picture.

On an individual level Brevis, Ngambi, Vrba and Naicker (2005) highlights values and attitude as basic beliefs that a certain way of doing things is preferable to another. However this principle operates as a guideline and foundation for an individual's values to choose between what is correct and incorrect. Brevis et al. (2005) further emphasised that attitude is a permanent and general evaluation of people, objectives, or events with an affective, behavioural and cognitive components. Nel et al. (2012) looked at organisational values emphasising on beliefs and ideas about goals that the organisation should pursue. These become appropriate standards of behaviour that support the organisation's management style and determine its attitude towards employees and shareholders, as well as its ethics. Although values and attitudes are essential their relevance at the workplace tends to be limited to job-related (Brevis et al., 2005).

\section{Mitigation of silo mentality formation for a firm}

Major weaknesses of silo mentality is that it tends to bring the distractions in a business and destabilises the operation of the business (Syverson, 2010). It is also a metaphor for organisational units that contain their own management team, talent and lack motivation or desire to work with /or even communicate with other organisational units (Gyrd-Jones et al., 2013). Mitigating silo formation requires an environment where employees are co-creators who advocate for the best ideas, regardless of their own individual roles in the organisation (Pratt, 2010). A process that has to start from the top management (Engle, 2011), align firms' functional goals with incentives and profits(Katunzi, 2011), strenghten interdepartmental dependencies to be linked with customer experience (Shaw, 2013).

Naseer (2014) strategies, goes beyond the individual attributes to incoporate group perspective(meso), and organisational relationship perspectives (macro) which are distinct from an individual (micro). These aim to; a)encourage mistakes and failures as opportunities to learn and improve; b) communicate a common purpose across divisions; c) redirect the team's competitive spirit toward external targets; d) encourage greater flexibility within and between teams; e) build trust across teams and departments. These were different yet somehow similar to Van Bruaene (2012) guidelines to rectify problems associated with the silo mentality with the organisation. Silo mentality can be minimised when information flows across, up and down, and within departments, priorities are aligned, decision are coordinated across departments and teams look across the compay for succesful previous collaborations (Wilhelm, 2013).

\section{Using business model canvas to create a firms'value}

Business models help firms to deal with market complexities, thus they need to be restructured to meet today's demanding and changing trends (Amit and Zott 2012, Demil and Lecocq 2014). They help create value (Chesbrough \& Rosenbloom, 2002) and have become key drivers for organisational performance, and products or services to sustain a competitive advantage. Using the 9 building blocks domian, value is determined in terms of product, customer interference, infrastructure management and financial aspects (Ostenwalder, Pigneur, and Tucci, 2005). This is known as business model canvas focused on value proposition (bundle of products and services), segments of customers, distribution channel, customer relations,value configuration (arrangement 
of activities and resources), core competency, partner network, cost structure which looked at monetary consequences and the revenue model (Ostenwalder et al.,2005).

\section{Methodology}

An exploratory study was selected where a qualitative research design was used to help explore the process and to give meaning (Cooper and Schindler, 2014:144). In-depth PICBE |1012 interviews wereconducted amongst 12 participants, selected using a convenience sampling method (Blanche Terre et al., 2006). Participants were from an enterprise business unit coming from operational level up till strategic management level as they dealt regularly with customers and could help ascertain how silo mentality affect value proposition and its delivery to customers. The research instruments focused on the silo mentality effects on divisional performance, customer experience, quality of products, value chain process and morale of individual teams.

The focus was on meaning, so as to make sense of a complex emerging situation (Kaplan and Maxwell, 1994). Content analysis was used which helped to present, determine, and analyse words and /or concepts within texts or sets of texts. This provided meaning, relationships to make inferences about the messages. Trustworthiness was based on validity and credibility (Denzin and Lincoln, 2003), however reliability of a content analysis depends on the stability, reproducibility and the accuracy of groupings and categorisations done.

\section{Findings}

Gaining an understanding to the meaning given to this concept participants viewpoint used words such as operating in isolation, not sharing/ withholding (skills, information and /or knowledge) failure to interact with others. These were prominent especially during problem solving or performing an operation which has direct impact to the organisational strategy. This was also seen as an organisational culture, a behaviour, a perception or a mindset.

Effects of silo mentality as seen in Figure 1 below highlights levels at which the formation of silo mentality affects the organisation. The four core areas affected identified included; innovation, customers, teams and departments. With the latter two focusing on working relations these also highlighted an intra and interdepartmental discourse linked to conflict and problem solving. 


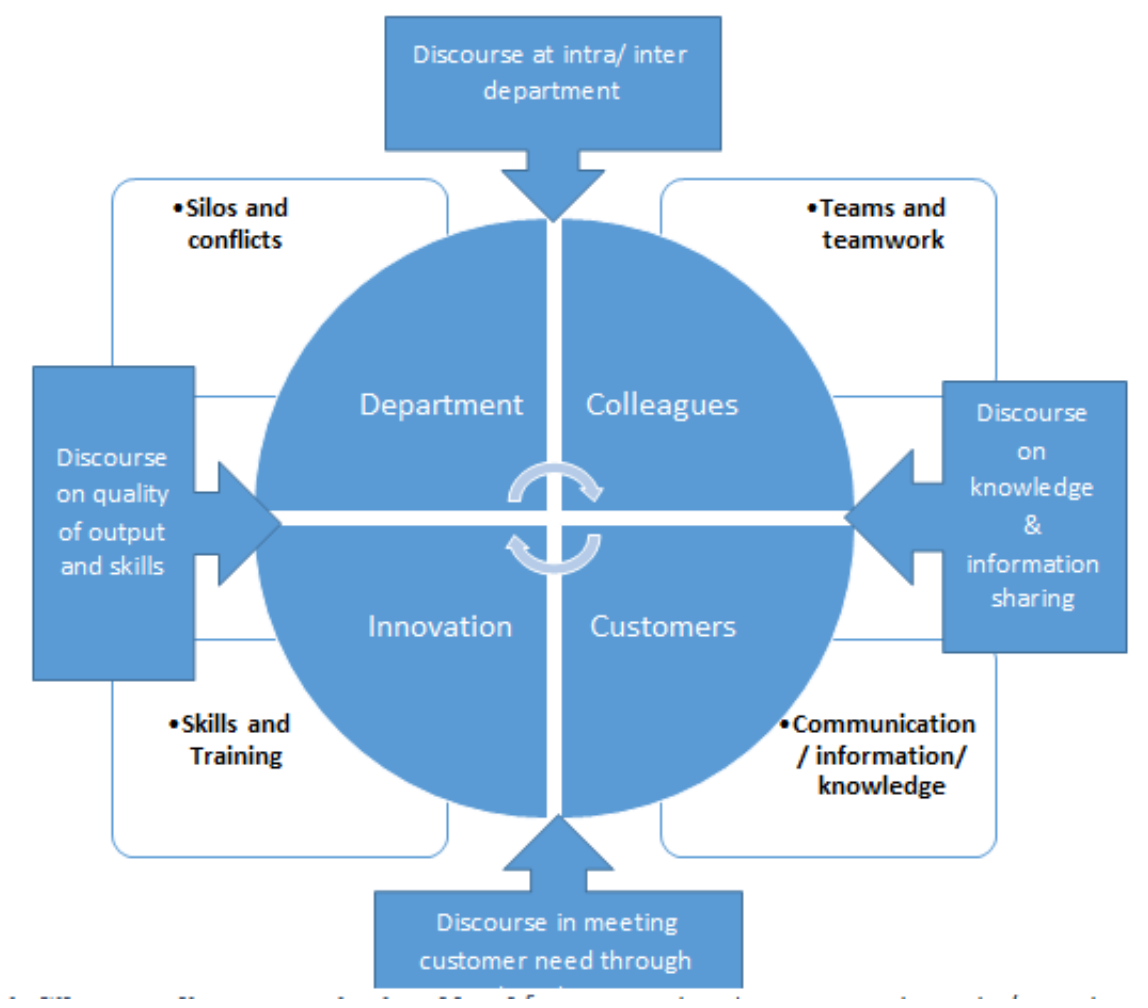

PICBE $\mid 1013$

Figure 1. Silo mentality at organisational level

Source: Authors' own research results/contribution.

When colleagues as experts fail to share information based on skills knowledge and expertise this tends to have ripple effects to customers creating a discourse on information sharing. If customer need are not aligned to trends, skills, new technology training then innovation tends to be affected creating a discourse in meeting customer needs. Finally when skills and knowledge are kept, not share due to silos these tends to create a discourse on quality, productivity and output such as;

- Conflicts between departments and colleagues due processes which are not aligned with customer's service demands.

- No teamwork within the divisions expected to work together for a common goal, causes the silo mentality.

- High individualism and lack of communication that contributes to silo formation.

- Lack of employee training to stay relevant for changing landscape and competitiveness

Regarding the negative effects of silo mentality within the organisation, few negative effects identified linked to the silo mentality are as follows;

- Decrease key performance (KPI)

- Failure to meet customer demands.

- Bottleneck challenges linked to value chain

- Quality service for customers gets affected

- Failure to provide distinct customer experience.

- Frustrated employees

- Inability to meet employer and employee contractual obligations.

- Underperforming HR (seen as a norm). 


\section{Levels affected by silo mentality}

The effects of silo mentality was at divisional or unit performance (team performance), quality (of product/ customer services) and how others impact on own productivity and performance output (individual's performance).

Table 1. Verbatim responses on silo effects and its understanding

\begin{tabular}{|c|c|}
\hline Levels & Quotes and words used \\
\hline $\begin{array}{l}\text { Effects at divisional } \\
\text { levels }\end{array}$ & $\begin{array}{l}\text { 'performance is adversely affected' 'hinders the performance of the section' } \\
\text { 'section performs badly ' 'performance deteriorates' 'Slows down the } \\
\text { performance' 'Degrading of the section performance. Affects company } \\
\text { performance as a whole.' 'something that can take you } 5 \text { minutes ends up } \\
\text { taking the whole hour'. }\end{array}$ \\
\hline Effect on quality & $\begin{array}{l}\text { 'Quality of service is compromised because jobs aren't done properly the first } \\
\text { time' 'Long delivery time equals poor customer service' 'There won't be quality } \\
\text { since fewer people will be working on the project' 'The quality of service } \\
\text { provided is not so great' 'It affects the quality as no one really takes ownership } \\
\text { of the problem' 'quality of the work decreases and customers become } \\
\text { unhappy' 'Quality is always not good as some of the skills employees were left } \\
\text { out' 'The quality will also be of a lower standard.... quality of the end } \\
\text { product/service will thus show that not the same type of effort was put'. }\end{array}$ \\
\hline $\begin{array}{l}\text { Effects of delays from } \\
\text { others } \\
\text { on own performance }\end{array}$ & $\begin{array}{l}\text { 'delay in service resulting in disgruntled customer and I cannot perform well', } \\
\text { 'unable to meet customer request, this results in myself been unable to reach } \\
\text { my performance obligations', 'because of delayed responses we come across as } \\
\text { unreliable to customers', 'my performance to my manager drops and cannot } \\
\text { give client information feedback'. 'Negatively impacts on Key Performance } \\
\text { Areas, which then slower service to customer' and 'a broken delivery promise } \\
\text { tends to sour up the whole customer relationship' }\end{array}$ \\
\hline $\begin{array}{l}\text { Own understanding of } \\
\text { silo mentality }\end{array}$ & $\begin{array}{l}\text { 'A mind-set within an organisation of withholding information from one another' } \\
\text { 'It is the mentality of certain organisation or individuals to withhold information' } \\
\text { 'when departments operate as individual business units with no regard for the } \\
\text { rest of the business as a whole' 'Working within your division and not interact } \\
\text { with the outside division' 'When a person doesn't want to work in teams and } \\
\text { share his or her skills with their co-worker'. }\end{array}$ \\
\hline
\end{tabular}

Source: Authors' own research results/contribution.

Prominently strong words that seems to portray negative response such as delays and lack of knowledge, absence of skills required to resolve faults, poor team performance, and ineffective problem solving methods. On quality effects words such as compromise quality (poor / lower standards), prolong delivery time and also destroy team unity were prominent.

\section{The individual vs. the organisation}

There was a significant reference to individuals, teams, groups, divisions, units and departments as the platforms at which silo mentality occurs. Although silo mentality was seen as an individual behaviour at times it was regarded an acceptable organisational behaviour, especially when it becomes a norm rather than an exception, meaning more and more people are seen practicing it. However it is unclear if the behaviour is frowned upon or is viewed as unacceptable organisational behaviour with punitive consequences. Instead consequences are viewed as effects of this behaviour

\section{Silo mentality as a process}

As a process silo mentality is seen as negative intended behaviour that is linked to failure to share, communicate or do what was expected to be an acceptable behaviour. 
Respondents used words such as intentions, cognitive and mental process to emphasis the intensity at which the behaviours present itself. This emphasised respondent's level of understanding. However, there were activities associated with silo mentality. It was viewed as the absence, reluctance or failure to do something. Actions such as cooperate, information sharing, skills and knowledge sharing with others. At some stage others, was qualified as 'those who need' or 'co-workers'. This intentional behaviour is seen as a cognitive process gets associated to a culture. Although it could not be clarified if it is organisational or individual's culture.

\section{Themes}

Individualism versus collectivism: Teams and departments seemed to view themselves as separate entities where separate behaviour (separateness) seems to reflect an organisational culture. Lack of collaboration, failure to be united (as a team), and leads to absence of ownership when there is a problem. Customer experience suffered because individualism tends to exist within the divisions and organisations. Singh and Signhi (2015) are of the opinion that individualistic cultural values emphasize selfreliance, autonomy, competition, personal control, and individual goals. Linked to this behaviour is the acceptable non- sharing \& separateness culture.

The non-sharing behaviour is not merely a behaviour but is also a perception, and a mindset. According to Vatanpour et al., (2013) they are of the belief that this type of mentality will reduce the efficiency of the overall operation, reduce morale, and may contribute to the demise of a productive company culture.

Organisational culture is characterised by closed group cohesion, non-sharing with those viewed as outsiders this tends to unite and strength the cohesion. Thus creating an organisational culture, a system of values and norms shared among a group of people (Hill, 2012). Brown and Harvey (2006) acknowledge that it starts with a subculture in one unit but view this change as positive as it leads to increased performance of the department, and ultimately the whole organisation gets motivated. This notion is further supported by Sandhu, (2011) as it encourages knowledge sharing which can be developed with the right incentives. Findings from this study seem to dispute these notions both Harvey \& Brown (2006) increased performance and Sandhu (2011)'s knowledge sharing as the opposite occurred.

Failure to connect strategy with operations can be viewed as operational gaps, leads to poor understanding of organisational strategy and inability to deliver through operations. This is linked to performance and measured through indicators. However strategic objectives for divisional level and amongst team member (of the same and / or different divisions) tend to unify employees to rectify silo mentality (Van Bruaene, 2012), meaning ranking strategic objectives or mission as highest priority in both thematic and concrete mechanism, rather than respective operating unit objectives to mitigate operational gaps.

\section{Discussions}

\section{Implication for the firm's business model}

Silo mentality affects diverse levels, this study adapted business model canvas (Ostenwalder et al., 2005) as indicated in figure 2 below to illustrate how value proposition (company's bundle of products and services) is compromised due to the delayed and poor quality.

Secondly the study indicate how strained relationships within team and with customers impacts customers negatively due poor services received. Silos harm 
customer experience, operations such as finance (cost and revue stream) and marketing leading to a disjointed firm (Buster, 2015). This affects different customer segments and leads to negative customer relations and key partners.

Clements and Gido (2012) are of the opinion that customers and suppliers want to do business with a contractor or project organisation they trust. When incompetence's and inefficiencies become the firms' norm these tend to affect trust not PICBE |1016 only from customer but also suppliers and key partners (Clements \& Gido 2012).

The non- sharing of skills, knowledge and information jeopardise key competencies necessary to execute the company's business model thus impact on the firm's key resources and capabilities. Katunzi (2011:108) is of the view that people get threatened by change and information sharing. However business model focus on cooperation, collaboration, partnerships and joint ventures (Zott et al. 2011, Magretta 2002).

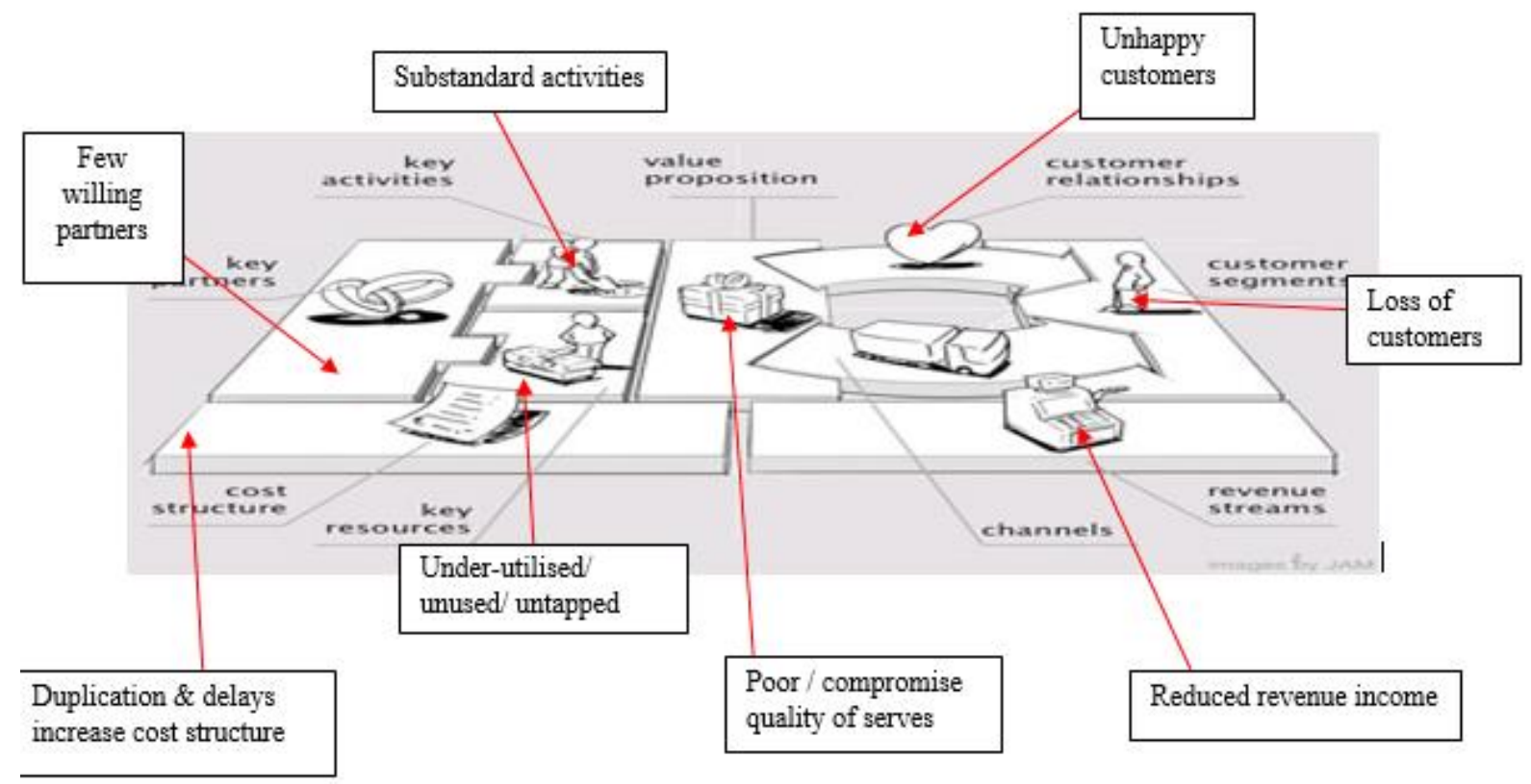

Figure 2. Effect of ITC firm's silo mentality

Source: Adapted Ostenwalder et al (2005)'s business model canvas.

When employees fail to meet key performance areas that seems to suggest that the firms' key activities gets compromised as value configuration based on the inadequate competencies necessary to execute the company's business model. Purna Sudhakar et al., (2011) are of the view that performance of a section will be positively or negatively affected by characteristics of having a clear goal, competent team members, result-oriented structure, collaborative climate, recognition, management support, motivation, high level of commitment

\section{Conclusions}

Corporates strive to achieve a competitive advantage through developing strong teams that are innovative in meeting customer needs and adding value. Yet through silo mentality the firms' resources gets affected at both individual and team level (interdivisional, intradepartmental and interdepartmental). Internal conflicts amongst teams and colleagues affect team cohesion, morale, delays achievements of common goals and enhance opportunities for individualism Whereas, weaker teams reduce firms' internal capabilities, undermined key resources, diminish teams performances hence, affecting productivity, prolong value chain when they underperform, fail to meet customer 
demands, compromise quality of services. Such bottlenecks do not only compromise the quality of service, but affect inter-divisional progress, elations at intra and interdepartmental and customer output and relations. This means a disjointed firm compromise its value proposition as its revenue reduce due unsatisfied customers and relations with partners, customers and stakeholders gets compromise. In conclusion, silo mentality is a bottleneck that limits and weakens firms' capabilities and growth potential thus destroying any value (proposition and constellation) created by the firm.

The two limitation for this study are linked to the selected unit and the time allocation. A focus on the enterprise unit might have produced a narrow view of the company's perspective. Strict time allocated by management was granted but limited probing as employees were concerned not to exceed allocated time.

\section{References}

Adams, G.B., \& Diamond, M.A. (1999). Psychodynamic perspectives on organizations: identity, politics and change. American Behavioral Scientist, 43(2), 221-224.

Amit, R., \& Zott, C. (2012). Creating value through business model innovation. MIT Sloan Management Review, 53(3), 41.

Bauer, T. \& Erdogan, B. (2012). Organisational Behaviour. v.1.1 ed. s.l.:Unnamed Publisher.

Betchoo, N.K. (2015). Managing Workplace Diversity: A Contemporary Context. Universite des Mascareignes: Nirman Kumar Betchoo and bookboon.com.

Blanche Terre M., Durrheim K., Painter D. (2007). Research in practice. Cape Town, RSA: University of Cape Town Press.

Brevis, T., Ngambi, H.C., Vrba, M.J. \& Naicker, K.S. (2005). Management Principles. . McGraw-Hill. Cape Town.

Brown, D.R. \& Harvey, D. (2006). An Experiential Approach to Organisation Development. New Jersey: Pearson Prentice Hall.

Buster, J. (2015). March Board. [Online] Available at: www.matchboard.com.au [Accessed 13 January 2017].

Cilliers, F., \& Greyvenstein, H. (2012). The impact of silo mentality on team identity: An organisational case study. SA Journal of Industrial Psychology, 38(2), 75-84.

Chesbrough, H. \& Rosenbloom, R.S. (2002). The Role of Business Model in Capturing Value from Innovation: Evidence from Xerox Corporation's technology spinoff companies. Industrial and Corporate Change, 11, 533-534.

Clements, J.P. \& Gido, J. (2012(. Effective project management. 5th ed. Australia: SouthWestern Cengage Learning.

Cooper, D.R. \& Schindler, P.S. (2014). Business Research Methods. United States of America: McGraw-Hill/Irwin.

Diamond, M.A., \& Allcorn, S. (2004). Moral violence in organisations: Hierarchic dominance and the absence of potential space. Organisational \& Social Dynamics, $4(1), 22-45$.

Diamond, M.A., \& Allcorn, S. (2009). Private selves in public organizations - The psychodynamics of organizational diagnosis and change. New York: Palgrave Macmillan.

Diamond, M.A., Allcorn, S., \& Stein, H.F. (2004). The surface of organizational boundaries: A view from psychoanalytic object relations theory. Human Relations, 57(1), 3153. 
Diamond, M.A., Stein, H.F., \& Allcorn, S. (2002). Organizational silos: Horizontal organizational fragmentation. Journal of the Psychoanalysis of Culture and Society, $7(2), 280-296$.

Demil B. \& Lecocq X. (2014). The Rise and Fall of an Open Business Model. The Business Model Community, Working Paper Series, 2014-01.

Denzin N.K. \& Lincoln, Y.S. (2003). The Landscape of Qualitative Research Theories and PICBE $\mid \mathbf{1 0 1 8}$ Issues. London, Sage Publication.

Engle, P., (2011). Breaking Down Silos. Industrial and Management Solutions at Work, 43(12).

Frederick, P.R.H. (2014). Organisational Behaviour and its Role in Management of Business. Global Journal of Finance and Management, 6(6), 563-568.

Greenberg, J., \& Baron, R.A. (2003). Behaviour in Organisations, eighth (international) edition.

Guba and Lincoln, (1994). Competing Paradigms in Qualitative Research. Thousand Oaks, CA Sage.

Gyrd-Jones, R. I., Helm, C. \& Munk, J., (2013). Exploring the impact of silos in achieving brand orientation. Journal of Marketing Management, 29(9), 1056-1078.

Hill, C. W., (2012). International Business: Competing in the global marketplace. New York: Mc Graw Hill.

Hotaran, I. (2009). Silo Effect versus supply chain effect. The Bucharest Academy of Economic Studies, Romania, 10(1), 216-217.

Kaplan, B., \& Maxwell, J. A. (1994). Evaluating health care information systems: Methods and applications. Qualitative Research Methods for Evaluating Computer Information Systems. JG Anderson, CE Ayden and SJ Jay. Thousand Oaks, Sage.

Katunzi, T.M. (2011). Obstacles to Process Integration along the Supply Chain: Manufacturing Firms Perspective. International Journal of Business and Management, 6(5), 105- 113.

Magretta J. (2002). Why Business Models Matter: A Conversation with Robert Redford: Harvard Business Review, 80(5), 86-92.

Naseer, T. (2014). Vistage. [Online] Available at: http://www.vistage.com. [Accessed 7 October 2015].

Nel, P.S., Werner, A., Poisat, P., Sono, T., Du Plessis, P., Ngalo, T., Van Hoek, L., Botha, C.J. (2012). Human Resources Management. Cape Town: Oxford University Press.

Ostenwalder A, Pigneur Y, and Tucci C.L. (2005). Clarifying Business Models: Origins, Present, and Future of the Concept, Communications of Association for Information System, 15, 1-43.

Purna Sudhakar, G., Farooq, A., \& Patnaik, S. (2011). Soft factors affecting the performance of software development teams. Team Performance Management: An International Journal, 17(3/4), 187-205.

Shaw, C., (2013). Beyond Philosophy: Building Great Customer Experience. [Online] Available at: http://www.beyondphilosophy.com. [Accessed 7 October 2015].

Singh, A.P., \& Singhi, N. (2015). Role of life events stress \& individualism-collectivism in predicting job satisfaction. Indian Journal of Industrial Relations, 51(2), 300-312.

Syverson, C. (2011). What determines productivity? Journal of Economic literature, 49(2), 326-365.

Van Bruaene, M. (2012). Advancing your organization. [Online] Available at: www.advancingyourorganization.com. [Accessed 13 January 2016]. 
Vatanpour, H., Khorramnia, A., \& Forutan, N. (2013). Silo effect a prominence factor to decrease efficiency of pharmaceutical industry. Iranian journal of pharmaceutical research: IJPR, 12(Suppl), 207.

Vermeulen, F., Puranam, P. \& Gulati, R. (2010). Change for Change's Sake. EBSCOhost, 88(6), 71-76.

Visvalingam S., \& Manjit S.S. (2011). Organisational culture's influence on tacit PICBE $\mid \mathbf{1 0 1 9}$ knowledge-sharing behaviour, Journal of Knowledge Management, 15 (3), 462 477

Volkan, V.D. (2009). Large-group identity:'Us and them'polarizations in the international arena. Psychoanalysis, Culture \& Society, 14(1), 4-15.

Whetten, D.A. (2006). Albert and Whetten revisited: Strengthening the concept of organizational identity. Journal of management inquiry, 15(3), 219-234.

Wilhelm, K. (2013). Making Sustainability Stick: The Blueprint for Successful Implementation. New Jersey: Pearson FT Press.

Zott, C., Amit, R. \& Massa, L. (2010).The Business Model: Theoretical Roots, Recent Development and Future Research, IESE Working Paper WP862. 